\title{
Acute Pancreatitis Revealing Cystic Dilatation of the Common Bile Duct: A Case Report
}

\section{Naouel Lemdaoui ${ }^{1,2}$, Raouf Menoura ${ }^{1,2}$, Abderraouf Bataiche ${ }^{1,2}$, Ha- kim Rahmoune ${ }^{3}$, Nada Boutrid ${ }^{3}$ and Soumia Satta ${ }^{1,2 *}$}

${ }^{1}$ General Surgery Department "B", Ben Badis University Hospital of Constantine, Algeria

${ }^{2}$ Faculty of Medicine, Consrantine-3 University, Algeria

${ }^{3}$ LMCVGN Laboratory, Faculty of Medicine, Setif-1 University, Algeria

*Corresponding Author: Soumia Satta, General Surgery Department “B”, Ben

Badis University Hospital of Constantine, Algeria.
Received: June 12, 2020

Published: June 30, 2020

(C) All rights are reserved by Soumia Satta., et al.

\section{Abstract}

Cystic dilatation of the common bile duct (CDCBD) is a rare congenital defect. More than half of the reported cases are pediatric and $80 \%$ are involving girls. Its symptomatology is often atypical and it is commonly of incidental discovery and rarely revealed by a severe complication like acute pancreatitis.

Keywords: Cystic Dilatation of the Common Bile Duct; Acute Pancreatitis; Surgery

\section{Introduction}

Cystic dilation of the common bile duct (CDCBD) is a rare malformation considered to be a congenital condition [1]. Its most accepted etiology is associated with a pancreaticobiliary maljunction [2]. It is discovered in more than half of cases in children [2] and has a clear female predominance with a female-to-male ratio of $3 / 1[3]$.

CDCBD has non-specific clinical symptomatology and can be diagnosed fortuitously or rarely due to a complication such as acute pancreatitis $[1,2]$.

The curative surgery by cysto-digestive anastomosis has been abandoned as CDCBD is considered as a precancerous condition. Complete resection of the common bile duct with biliary-digestive anastomosis is currently the gold standard method $[1,4,5]$.

\section{Case Description}

We received in the surgical emergency ward a 65-year-old patient, with a previous history of cholecystectomy. She was complaining of diffuse, atypical abdominal pain associated with vomiting and acute diarrhea evolving for 48 hours.
Clinical examination noted stable hemodynamics, with moderate acute dehydration, along with abdominal tenderness more pronounced in regard of the epigastrium.

Biological assessment is carried out revealing a lipasemia $>$ than 4 times the upper limit of normal, highly suggestive of acute pancreatitis.

An abdomen ultrasound revealed a hypotonic common bile duct at its hilar portion without visualization of the choledochal duct.

Abdominal CT-scan performed 72 hours after the onset of pain showed an enlarged cephalic portion of the pancreas with high densification of the peri-pancreatic fat, confirming a stage $\mathrm{C}$ acute pancreatitis according to the Balthazar classification.

A second scanner (Figure 1) is carried out showing a cystic dilation of the common bile duct without any visible obstacle.

An additional magnetic resonance cholangio-pancreato-graphy MRCP (Figure 2) confirmed the diagnosis of choledochal cyst type Ic according to Todani; without lithiasic or tumoral obstacle in the duodeno-pancreatic block. 

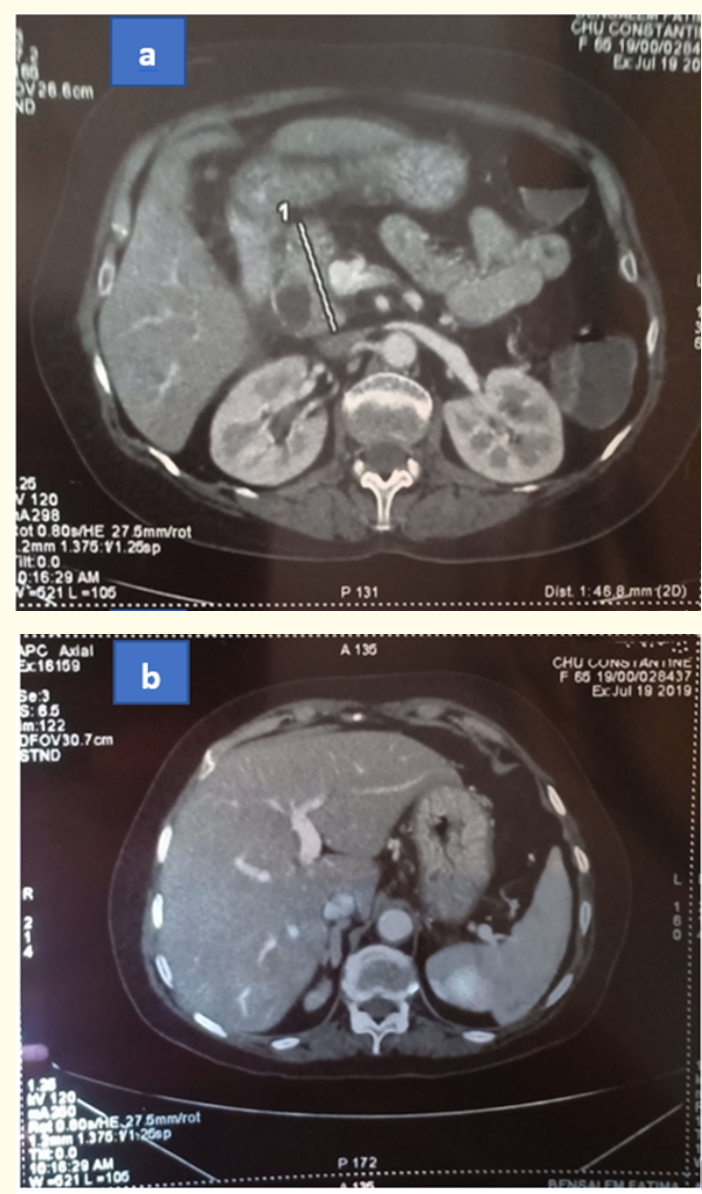

Figure 1: Abdominal CT Scan - a: Enlarged pancreas' cephalic portion $=47 \mathrm{~mm}$ and densification of the surrounding fat; $\mathrm{b}$ :

Dilated common bile duct.

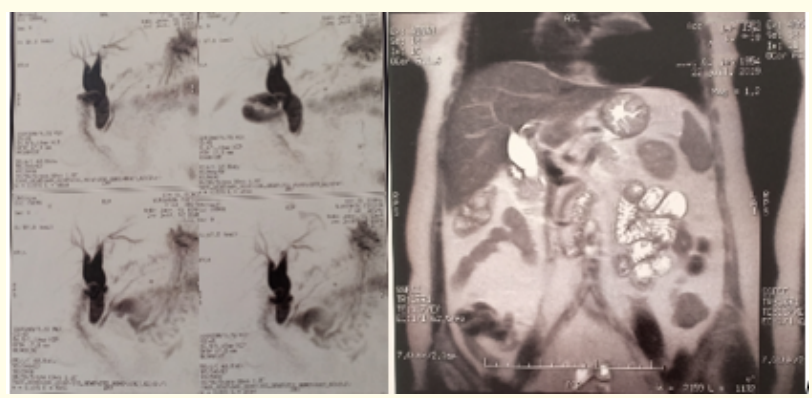

Figure 2: MRCP imaging: fusiform CDCBD Type Ic of Todani.
After complete resolution of this first episode of pancreatitis and adapted rehabilitation, the patient was operated at 03 months.

Kocher's manoeuvre revealed a thin common bile duct in the hilar portion of the common bile duct, and dilatation in the rest of its length.

Due to the high risk of recurrent pancreatitis and of secondary malignancy, total resection of the common biliary duct, below the convergence up to the papilla, is performed; respecting the Wirsung duct at the Vater's bulb (Figure 3), along with cholecystectomy.

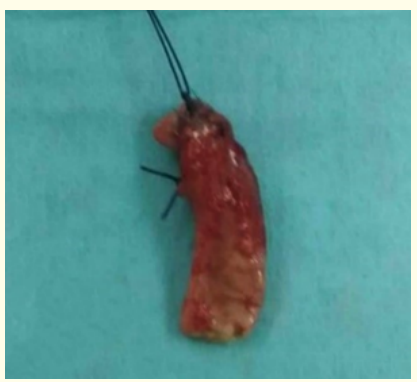

Figure 3: Common bile duct dilated, totally resected (the long black wire indicates the upper extremity).

No cholangiography is needed (satisfactory cholangio-MRI and total resection of the extra hepatic biliary tract).

A hepato-jejunal anastomosis in trans-meso-colic on a jejunal loop mounted in $\mathrm{Y}$ and drainage opposite the anastomosis are performed (Figure 4).

The post-operative outcomes are simple. The pathology of the resected part found a fibro-congestive tissue, free of any tumour lesion.

\section{Discussion}

Ductal dilatation of the biliary tree was first reported by Vater in 1723 and fully clinically, described by Douglas in $1852[3,5]$.

Choledochal cyst is a rare congenital malformation [6] with an incidence of the order of $1 / 13,000$ to $1 / 200,000$ live births [7]. It is often seen in children $75 \%$ of cases discovered before the age 


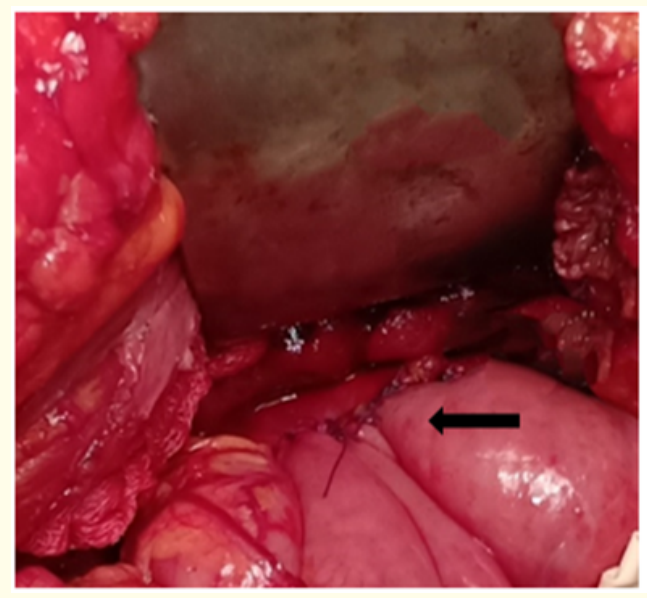

Figure 4: Hepato-jejunal anastomosis.

of 10 ), with a clear female predominance $[1,8]$. It is defined as a CDCBD without abnormality in the cystic duct, gallbladder or intrahepatic bile ducts [2].

Pathophysiology remains unclear, and abnormal biliopancreatic junction is the most accepted hypothesis [7]. Our patient has no abnormality of this junction.

When this dilatation symptomatic, the classic triad associating jaundice, pain of the right hypochondrium and palpable mass would only be observed in 15 to $25 \%$ of cases [7]. In most cases, the symptomatology comes down to abdominal pain in adults and jaundice in children [5]. In our observation, this malformation was revealed by acute pancreatitis (AP), although, more often it remains incidental [7].

Occurrence of acute pancreatitis with an abnormal pancreaticobiliary junction is more frequent in children (30\%) than in adults (9\%) with the same malformation [3] and recurrent pancreatitis is not uncommon [2]. Other complications can be seen, mainly due to stasis, which are: biliary lithiasis, infection, and even portal hypertension, biliary cirrhosis and biliary peritonitis [2]; the most serious remains the cancerization of the cyst wall (up to $28 \%$ cases reported in the literature) [2]. Thus, the choledochal cyst was recognized as a precancerous condition since 1944 [5].

The diagnosis of choledochal cyst is currently based on non-invasive imaging (ultrasound-CT, cholangio-CT, cholangio-MRI) [2]. In our observation, ultrasounds could not confirm the diagnosis; while CT- scan and cholangio-MRI were dramatically helpful showing the causal cystic malformation.

Cystic dilatations of the bile ducts encompass several types, depending on the site, the form and the distribution of the abnormality [4]. MRCP classified this case according to Todani as Type Ic. Todani classification (Figure 5) is the most used classification, with 5 major types and several subtypes $[7,9]$. The most common type is type I ( $80 \%$ of cases), due to a dilation of the pathway common bile. Type I itself is divided into 3 subtypes: Ia = sacciform dilatation of the entire common bile duct but respecting biliary convergence, Ib = segmental dilatation and Ic = fusiform, segmental or diffuse dilatation which can reach biliary convergence. This last subtype was the one observed in our patient. The other types are Type II (10\%): supraduodenal bile duct diverticulum; Type III (4\%): Choledococele, Type IV (11\%); a: dilatation of the intra- and extra-hepatic bile ducts, b: multisegmental dilatation of the common bile duct and Type $\mathrm{V}(<1 \%)$ : Isolated dilatation of the intrahepatic bile ducts $[4,10]$.

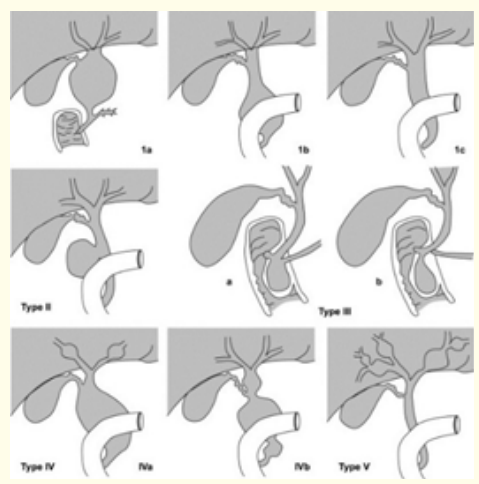

Figure 5: Todani's classification of congenital cystic dilatation.

Operating techniques vary depending on the type of malformation [11]. Resection of cystic dilatation is the standard treatment [5] after systematic cholecystectomy (if the gallbladder is present) and disconnection of the common bile duct and Wirsung, along with a biliodigestive anastomosis [2].

This surgery was successful in our patient with no post-operative complications such as anastomotic fistula or stenosis, more frequent after cysto-diversions [5]. 
In the literature, we found peculiar similar cases of acute pancreatitis revealing CDCBD like those by Kabbaj., et al. in a 23-yearold patient [2], Mannai., et al. in a male patient [4] and El Khabiz., et al. in two adults [11].

\section{Conclusion}

CDCBD is a rare malformation that might remain silent or be revealed by acute complications like a pancreatitis.

Thanks to modern investigative methods, recent advances in resuscitation and improved surgical techniques, the overall prognosis of this condition greatly improved.

Total removal of the common bile duct with biliary-digestive anastomosis is the most recommended surgery.

\section{Acknowledgements}

N. Lemdaoui, H. Rahmoune and N. Boutrid are running projects with the Directorate General for Scientific Research and Technological Development (DGRSDT), MESRS, Algeria.

\section{Bibliography}

1. Ahmed A., et al. "Kyste du cholédoque rompu: revue de la literature". The Pan African Medical Journal 33 (2019).

2. Kabbaj N., et al. "Apropos of a case of acute pancreatitis revealing cystic dilatation of the common bile duct". Journal de radiologie 79.11 (1998): 1393-1397.

3. Kamisawa T., et al. "Pancreaticobiliary maljunction and congenital biliary dilatation". The Lancet Gastroenterology and Hepatology 2.8 (2017): 610-618.

4. Mannai S., et al. "Les dilatations kystiques congénitales des voies biliaires". 131 (2006): 369-374.

5. FAÏK M., et al. "Dilatation kystique du choledoque à propos de 8 cas" 75 (1999): 23-27.

6. Savić Dj., et al. "Kongenitalna dilatacija zucnih puteva (kongenitalna cista holedohusa [Congenital dilatation of the common bile duct (congenital choledochal cyst)]". Srpski arhiv za celokupno lekarstvo 129 (2001): 47-50.
7. Bouali O., et al. "Péritonite biliaire par rupture traumatique d'un kyste du cholédoque [Biliary peritonitis after traumatic rupture of a choledochal cyst]". Archives of Pediatrics 22.7 (2015): 763-766.

8. Dhupar R., et al. "The changing presentation of choledochal cyst disease: an incidental diagnosis". HPB Surgery (2009): 103739.

9. Todani T., et al. "Congenital bile duct cysts: classification, operative procedures, and review of thirty-seven cases including cancer arising from choledochal cyst". The American Journal of Surgery 134.2 (1977): 263-269.

10. Vullierme MP., et al. "Dilatation kystique congénitale de la voie biliaire principale. Corrélations radio-anatomiques chez 14 malades [Congenital cystic dilatation of the common bile duct. Radio-anatomical correlations in 14 patients]". Gastroentérologie Clinique et Biologique 21.3 (1997): 201-208.

11. El Khabiz Nawal., et al. "Les Dilatations kystiques congénitales des voies biliaires, à propos de 14 cas". Poster presented at: Journées Franophones d'Hépato-gastroentérologie et d'oncologie digestive. Paris, France (2017).

\section{Assets from publication with us}

- Prompt Acknowledgement after receiving the article

- Thorough Double blinded peer review

- Rapid Publication

- Issue of Publication Certificate

- High visibility of your Published work

Website: www.actascientific.com

Submit Article: www.actascientific.com/submission.php Email us: editor@actascientific.com

Contact us: +919182824667 